\title{
Stereotactic body radiotherapy (SBRT) for non- pathologically diagnosed lung cancer patients
}

\author{
Matthew M. Harkenrider, Matthew H. Bertke, Neal E. Dunlap, Anthony E. Dragun \\ Department of Radiation Oncology, James Graham Brown Cancer Center, University of Louisville Hospital, School of \\ Medicine, 529 South Jackson Street, Louisville, KY 40202, USA
}

Correspondence: Matthew M. Harkenrider. Address: Department of Radiation Oncology, James Graham Brown Cancer Center, University of Louisville Hospital, School of Medicine, 529 South Jackson Street, Louisville, KY 40202, USA. Telephone: 502-561-2700. Fax: 502-561-2709. E-mail: mmhark01@louisville.edu

Received: March 6, 2012

DOI : $10.5430 /$ jst.v2n3p4
Accepted: April 6, $2012 \quad$ Published: June 1, 2012

URL: http://dx.doi.org/10.5430/jst.v2n3p4

\section{Abstract}

Objective: Medically inoperable patients with primary or recurrent lung cancer are increasingly being diagnosed clinically without pathologic confirmation especially for patients with comorbidities that preclude biopsy. The objective of this study is to report the outcomes of medically inoperable patients with unbiopsied primary or recurrent lung carcinoma with SBRT.

Methods: From 2008-2011, 22 patients with non-pathologically diagnosed primary or recurrent lung cancer were treated with SBRT. All patients had diagnostic imaging clinically consistent with primary or recurrent lung malignancy. Fifteen patients had primary lung cancer and 7 had recurrent disease previously treated with surgery or fractionated radiotherapy. Median SBRT dose was 50 Gy (Range 40-55 Gy) in a median of 5 fractions (Range 4-10 fractions). Median BED was 100 Gy (Range 72-151.2 Gy).

Results: Median follow up is 15.3 months (Range 6.6-33.0 months). Primary tumors had a median longest dimension on the original CT of $1.6 \mathrm{~cm}$, which enlarged to $2.0 \mathrm{~cm}(P<0.001)$ on serial CT and decreased to $1.3 \mathrm{~cm}(P=0.003)$ after SBRT. Recurrent tumors had a median longest dimension of $1.6 \mathrm{~cm}$, which increased to $2.7 \mathrm{~cm}(P=0.33)$ on repeat $\mathrm{CT}$ and subsequently stabilized at $2.7 \mathrm{~cm}$ after SBRT. On FDG-PET scan, median standard uptake value (SUV) for the entire population is 5.4 before SBRT which decreased to $2.3(P<0.001)$ after treatment. For the entire population, absolute local control was $90.9 \%$. Kaplan-Meier curves estimates at 2 years show regional control $100 \%$, distant control $75 \%$, cancer specific survival $92 \%$, and overall survival $75 \%$. There were no grade $3 / 4$ acute or chronic treatment-related toxicities. Conclusions: In medically inoperable patients, a diagnosis of lung cancer can be provisionally made radiographically without pathologic confirmation. Local control can be achieved with minimal toxicity with the use of SBRT.

\section{Key words}

SBRT, Stereotactic, Lung Cancer, Unbiopsied, Recurrent

\section{I ntroduction}

Patients with early stage non-small cell lung cancer are optimally treated with lobectomy and mediastinal lymph node dissection which yields a locoregional control rate of approximately $93 \%{ }^{[1]}$. The Lung Cancer Study Group reported a randomized trial of lobectomy versus sublobar resection for peripheral T1 lung carcinoma with local relapse rate of $6.4 \%$ 
and $17 \%$, respectively ${ }^{[2]}$. In medically inoperable patients, conventionally fractionated radiotherapy for early stage lung carcinoma has shown local control rates of only $30 \%-40 \%{ }^{[3-5]}$. In the last decade stereotactic body radiotherapy (SBRT) has been described by many institutions and recently by the RTOG with local control rates comparable to lobectomy in medically inoperable patients ${ }^{[6-11]}$.

Many patients with lung cancer have multiple comorbid conditions such as chronic obstructive pulmonary disease and cardiovascular disease making them suboptimal candidates for lobectomy or making them medically inoperable. Unfortunately, some patients have radiographic indications of lung carcinoma, such as increasing size of a pulmonary nodule on serial CT scans and/or a hyper metabolic nodule on PET/CT, yet are unable or unwilling to undergo biopsy. The greatest risk factor with CT-guided biopsy is pneumothorax, which is especially concerning for patients with severe COPD. Reported pneumothorax rates are as high as $27 \%^{[12]}$. Few studies report on patients treated with SBRT without tissue diagnosis due to the associated risks. In those reports $22 \%-69 \%$ of patients were diagnosed and treated based on malignant radiographic characteristics ${ }^{[13-17]}$. There is a dearth of information in the medical literature describing the outcomes of SBRT for unbiopsied primary early stage lung cancer patients.

Additionally, patients treated with conventional radiotherapy with or without concurrent chemotherapy for locally advanced lung cancer have few salvage options in the event of local failure without distant disease. Salvage options would include chemotherapy, radiofrequency ablation, conventional re-irradiation, SBRT, or best supportive care. There is little information in the published literature regarding the use of SBRT for radiographically diagnosed local recurrence of NSCLC. The purpose of this report is to describe the clinical indicators, outcomes, and toxicities of patients treated with SBRT for non-pathologically diagnosed primary or recurrent carcinoma of the lung.

\section{Patients and methods}

With approval of our institutional review board, we reviewed all patients treated with SBRT for primary or recurrent carcinoma of the lung at our institution from 2008-2011. We identified 22 patients that had lesions treated with SBRT without histologic diagnosis with at least 6 months of follow up. Surgical resection is our institutional standard of care for lung nodules that are biopsy-proven or radiographically diagnostic of malignancy. For patients with previously treated localized or locally advanced lung cancer, biopsy is preferred to validate treatment failure before progressing to salvage therapy. All patients in this study were deemed high risk for resection and/or biopsy by the thoracic surgeon if he determined that the risk of pneumothorax or perioperative morbidity/mortality precluded the procedure. Fifteen patients included in this study had primary lung lesions and were determined to have an unacceptable risk of morbidity related to surgical resection, transbronchial biopsy, or image-guided biopsy. Four patients had biopsies attempted that were nondiagnostic for carcinoma but were radiographically diagnostic of malignancy. Two patients had two lung nodules, one of which was diagnostic though biopsy of the other was not attempted. Patients with two peripheral lung nodules are classified as synchronous primary lung cancers for the purpose of this study with the unbiopsied lesion included in the study. Seven patients had lesions located in regions of previously treated NSCLC with imaging consistent with disease persistence or recurrence.

All patients underwent pre-treatment imaging consisting of chest $\mathrm{CT}$ with or without whole body PET/CT. All primary patients had high radiographic suspicion of malignancy based on the presence of a spiculated lung nodule that is enlarging on serial CT with or without hypermetabolic activity on FDG-PET imaging or two malignant appearing lung nodules with one pathologically diagnosed as malignancy. Recurrent or persistent disease shows similar radiographic characteristics in a previously treated site of parenchymal disease. Only patients with parenchymal lung lesions were included in this study. Patients were not excluded from this study based on lesion size or proximity to central structures as described by Timmerman, et al. ${ }^{[18]}$. 
The SBRT planning process for all patients follows the The American Association of Physicists in Medicine Task Group $101^{[19]}$. Briefly, treatment planning was initiated with four-dimensional CT (4D-CT) simulation scan in a vacuum-molded immobilization device. Respiratory gating or abdominal compression was utilized during treatment for patients with tumor motion greater than $1 \mathrm{~cm}$ in any dimension. Maximum intensity projection (MIP) from the 4D-CT was constructed for patients that did not require respiratory gating. The MIP delineates where the tumor is located within the patient during all phases of the respiratory cycle. The lesion was segmented based on the MIP and designated as the internal target volume (ITV). Planning target volume (PTV) was generated from the ITV with a uniform $5 \mathrm{~mm}$ margin. Cone-beam CT scan was performed with physician verification prior to each treatment to ensure proper alignment. All patients were treated using static field SBRT or volumetric modulated arc therapy (VMAT) with $6 \mathrm{MV}$ photons. Median total dose delivered was 50 Gy (Range 40-55 Gy) in a median of 5 fractions (Range 3-10). Median total treatment time was 15.5 days (Range 5-29 days). Median biological equivalent dose (BED) delivered was $100 \mathrm{~Gy}$ (Range 72-151.2 Gy), assuming an $\alpha / \beta$ for tumor of 10 Gy. All patients had post-treatment imaging with CT or PET/CT 6-8 weeks after completion of SBRT and then every 3-6 months.

The primary endpoint of the study is local control. Secondary endpoints include regional failure-free survival, distant metastasis-free survival, cancer-specific survival, overall survival, acute toxicity, and chronic toxicity. Kaplan-Meier curves were generated to estimate the treatment outcome endpoints in this study. Radiographic changes in the lesions were performed using a one-sided paired t-test. The greatest dimension of the tumor on CT imaging was used for analysis of response to SBRT. Response rates were classified radiographically according the RTOG 0915 CT-based response criteria ${ }^{[20]}$.

\section{Results}

From 2008-2011, 22 patients with unbiopsied primary or recurrent carcinoma of the lung were treated with SBRT at our institution, and patient characteristics are outlined in Tables 1 and 2, respectively. Median follow up is 15.3 months (Range 6.6-33.0 months) with a mean of 16.9 months. None of the patients in this study had a pathologic diagnosis, and reasons that biopsy was not obtained in these patients are outlined in Table 3. In the three patients that pathologic diagnosis was attempted, the modality employed was CT-guided biopsy in 2 patients and transbronchial biopsy with washings in 1 patient.

Table 1. Characteristics of patients with primary carcinoma ( $\mathrm{n}=15)$

\begin{tabular}{ll}
\hline Characteristic & Value \\
\hline Age (y) & 76 \\
Median & $57-87$ \\
Range & \\
Gender (n) & 11 \\
$\quad$ Male & 4 \\
Female & \\
Tumor size (cm) & 2.0 \\
$\quad$ Median & $1.0-4.5$ \\
Range & 13 \\
T stage (n) & 2 \\
T1 & \\
T2 & 80 \\
KPS (\%) & $70-100$ \\
Median & \\
Range & 50 \\
SBRT dose (Gy) & $50-55$ \\
Median & \\
Range &
\end{tabular}


Table 2. Characteristics of patients with recurrent carcinoma $(n=7)$

\begin{tabular}{|c|c|}
\hline Characteristic & Value \\
\hline \multicolumn{2}{|l|}{ Age (y) } \\
\hline Median & 72 \\
\hline Range & $53-83$ \\
\hline \multicolumn{2}{|l|}{ Gender (n) } \\
\hline Male & 5 \\
\hline Female & 2 \\
\hline \multicolumn{2}{|l|}{ Tumor size $(\mathrm{cm})$} \\
\hline Median & 2.7 \\
\hline Range & $1.3-6.3$ \\
\hline \multicolumn{2}{|l|}{ T stage (n) } \\
\hline $\mathrm{T} 1$ & 2 \\
\hline $\mathrm{T} 2$ & 4 \\
\hline $\mathrm{T} 3$ & 0 \\
\hline $\mathrm{T} 4$ & 1 \\
\hline $\mathrm{N}$ stage (n) & 5 \\
\hline N0 & 4 \\
\hline N1 & 0 \\
\hline $\mathrm{N} 2$ & 1 \\
\hline N3 & 1 \\
\hline \multicolumn{2}{|l|}{ KPS (\%) } \\
\hline Median & 80 \\
\hline Range & $40-100$ \\
\hline \multicolumn{2}{|l|}{ Previous tumor histology } \\
\hline Squamous & 4 \\
\hline Adenocarcinoma & 1 \\
\hline NSCLC (Not specified) & 1 \\
\hline Small cell & 1 \\
\hline \multicolumn{2}{|l|}{ Previous treatment } \\
\hline Wedge resection & 1 \\
\hline RT alone & 4 \\
\hline Sequential chemo/RT & 1 \\
\hline Concurrent chemo/RT & 1 \\
\hline \multicolumn{2}{|l|}{ Previous RT } \\
\hline $70 \mathrm{~Gy}$ & 3 \\
\hline $55-60 \mathrm{~Gy}$ & 3 \\
\hline None & 1 \\
\hline \multicolumn{2}{|l|}{ SBRT dose (Gy) } \\
\hline Median & 50 \\
\hline Range & $40-50$ \\
\hline
\end{tabular}

Table 3. Reasons pathologic diagnosis was not achieved $(\mathrm{n}=22)$

\begin{tabular}{lll}
\hline Biopsy Status & Patients & \% of Patients \\
\hline Not attempted due to comorbidities & 8 & $36 \%$ \\
COPD \& Pneumothorax risk $(\mathrm{n}=6)$ & & \\
Prior lobectomy with COPD $(\mathrm{n}=1)$ & & \\
Prior pneumonectomy $(\mathrm{n}=1)$ & 7 & $32 \%$ \\
Imaging defined local recurrence & 3 & $14 \%$ \\
Non-diagnostic biopsy performed & & $9 \%$ \\
Pulmonary hemorrhage (n=2) & 2 & $9 \%$ \\
Synchronous lesion not biopsied & 2 & \\
Patient refusal & & \\
\hline
\end{tabular}


Figure 1 describes the changes in the longest tumor dimension before and after SBRT for the 15 primary lung cancer patients. Median longest dimension of the primary lung tumor on the patients' original CT scan is $1.6 \mathrm{~cm}$ (Range $0.5-3.2$ $\mathrm{cm}$ ), subsequent pretreatment CT scan is $2.0 \mathrm{~cm}$ (Range $1.0-4.5 \mathrm{~cm})(P<0.001)$, and post-SBRT CT scan is $1.3 \mathrm{~cm}$ (Range $0.0-3.6 \mathrm{~cm})(P=0.003)$. Median pretreatment standard uptake value (SUV) for primary lung cancer patients with initial PET scans is 5.4 (Range 1.6-10.7) and post-treatment SUV is 2.3 (Range 0.0-4.5) $(P=0.005)$. Median time from end of treatment to most recent PET is 10.2 months.

Figure 2 shows the longest tumor dimension changes before and after SBRT for the 7 recurrent patients. Median longest dimension of tumor on the patients' CT scan at the time that surveillance began is $1.6 \mathrm{~cm}$ (Range $0.0-10.0 \mathrm{~cm}$ ), subsequent CT scan is $2.7 \mathrm{~cm}$ (Range $1.3-6.3 \mathrm{~cm})(P=0.33)$, and post-SBRT CT scan is $2.7 \mathrm{~cm}$ (Range $0.0-9.8 \mathrm{~cm})(P=0.49)$. Median pretreatment SUV for recurrent lung cancer patients is 5.6 (Range 1.5-11.5) and post-SBRT is 2.3 (Range 0.9-3.9) $(P=0.03)$. Median time from end of treatment to most recent PET is 9.6 months.

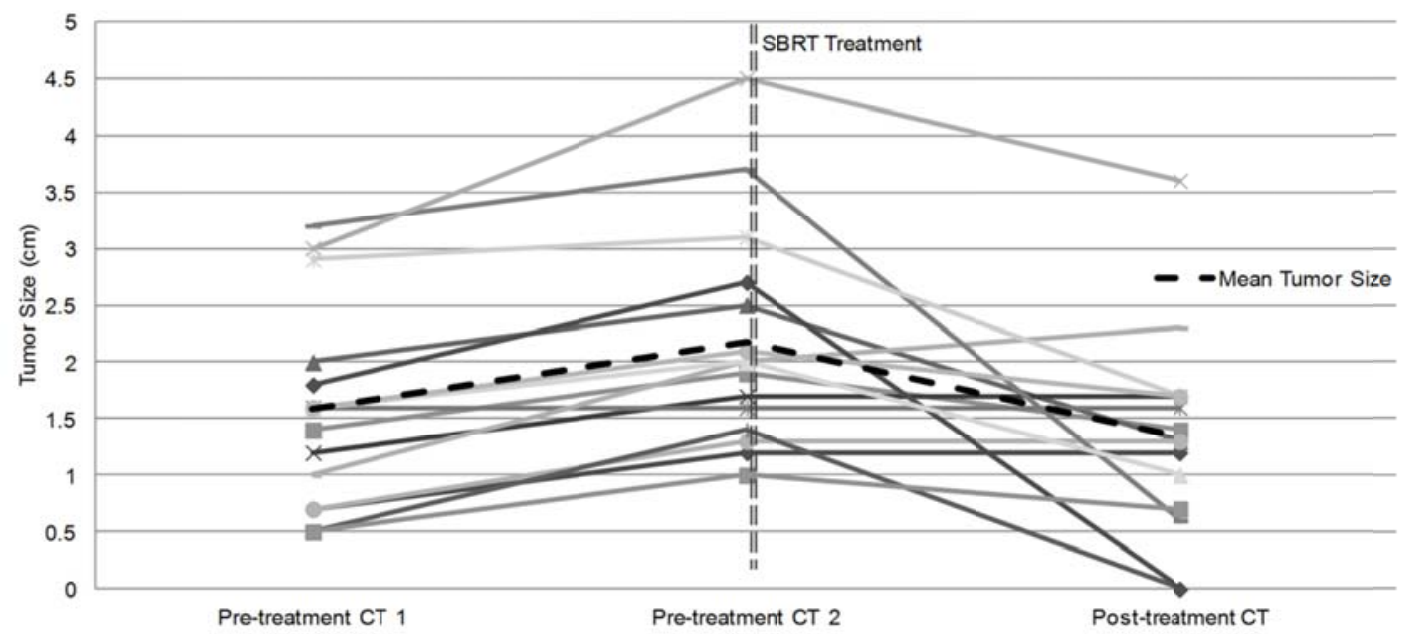

Figure 1. Changes in tumor size before and after treatment in patients with primary carcinoma $(n=15)$

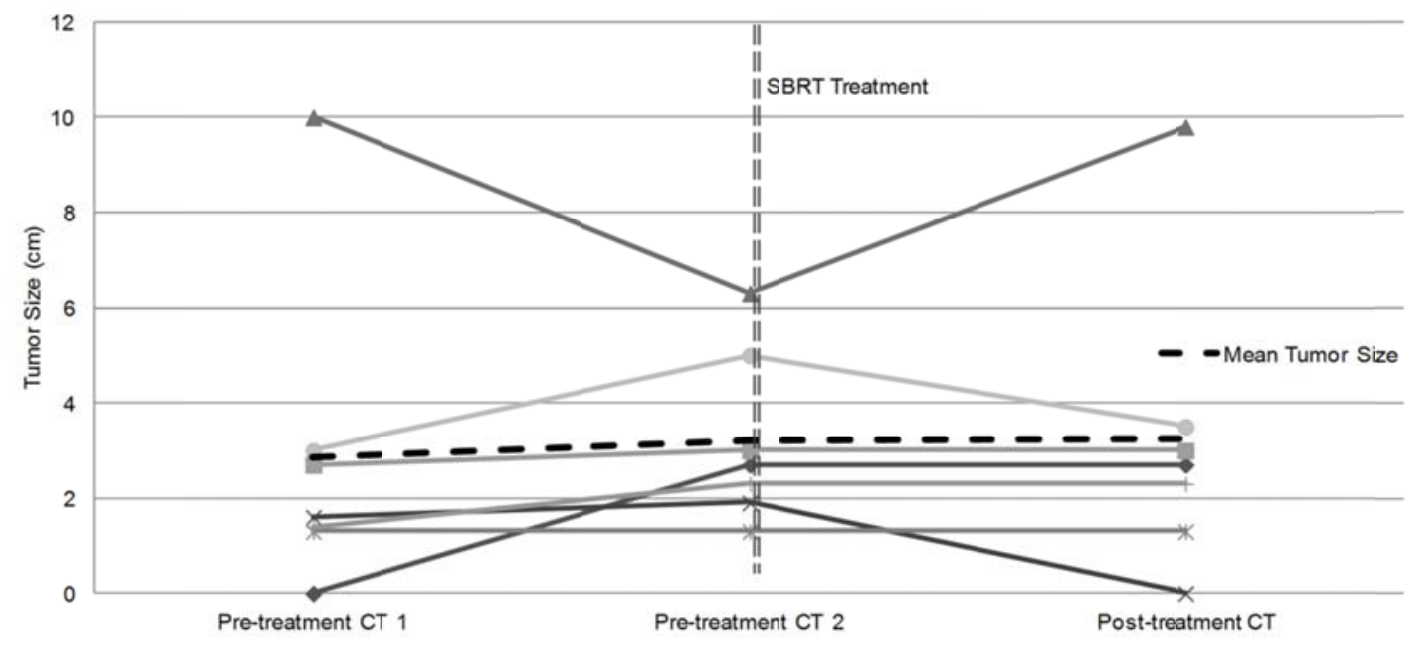

Figure 2. Changes in tumor size before and after treatment in patients with recurrent carcinoma $(n=7)$ 
None of the patients on this study encountered any acute grade 3/4 toxicity during the course of radiotherapy. In addition, none of the patients encountered any chronic grade 3/4 chronic toxicity on follow up. Eight of 22 patients had radiographic changes of the lung parenchyma including 4 with radiation pneumonitis, 2 with interstitial opacities, 1 with radiation fibrosis, and 1 with mass-like consolidation. No radiographic changes were symptomatically apparent.

Table 4 describes tumor control outcomes with the corresponding RTOG Response Criteria. Kaplan-Meier estimates of the endpoints are presented in Figure 3. For the entire population, absolute local control is $90.9 \%$ and Kaplan-Meier estimate at 2 years is $87 \%$. Both patients with local enlargements were in the recurrent group that failed initial therapy. Kaplan-Meier estimate of 2-year regional-failure free survival and distant metastasis-free survival are $100 \%$ and $75 \%$, respectively. Sites of distant failure include the lung in 2 patients, liver in 1 patient, and brain in 1 patient. Four patients died during the follow up period, but only one had active disease (metastatic) at the time. Three patients died of other causes, all with stable local disease without distant metastases. One patient with distant metastases has entered Hospice care. Kaplan-Meier estimate of 2-year cancer-specific survival and overall survival are $92 \%$ and $75 \%$, respectively.

Table 4. Tumor control outcomes $(n=22)$

\begin{tabular}{llll}
\hline Response & Patients & \% Patients & Definition \\
\hline Complete response & 3 & $13.6 \%$ & Disappearance of the target lesion \\
Partial response & 7 & $31.8 \%$ & At least a 30\% decrease in the LD of the target lesion \\
Stable disease & 10 & $45.5 \%$ & Between $30 \%$ decrease and $20 \%$ increase in LD of target lesion \\
Local enlargement & 2 & $9.1 \%$ & At least a 20\% increase in the LD of the target lesion \\
Overall local control & 20 & $90.9 \%$ & LD = Longest Diameter \\
\hline
\end{tabular}

(a)

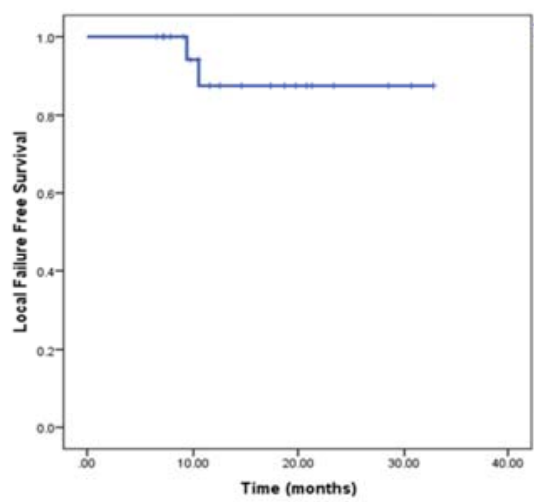

(c)

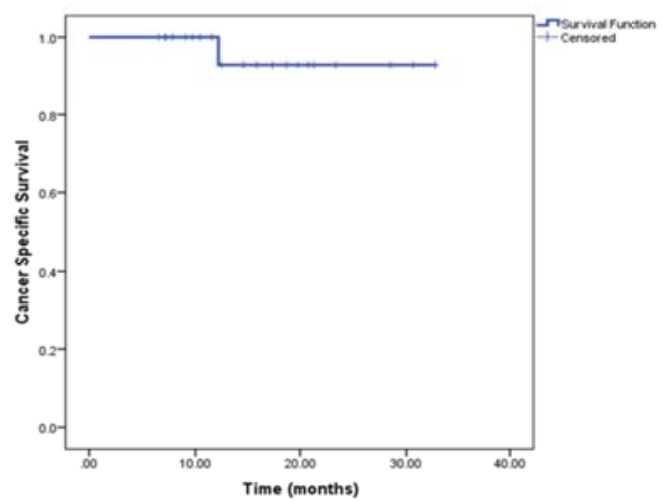

(b)

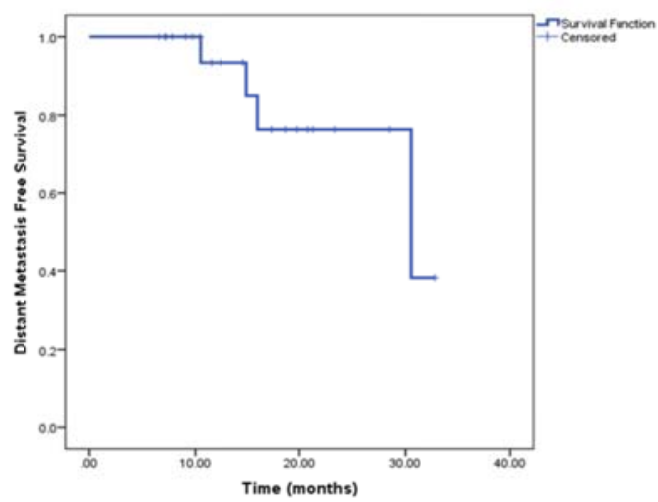

(d)

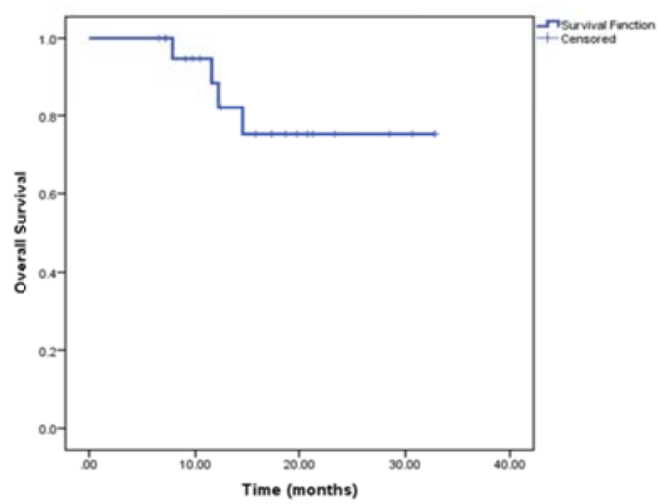

Figure 3. Kaplan-Meier estimates of treatment outcomes $(\mathrm{n}=22)$ 


\section{Discussion}

The presence of multiple comorbidities like COPD and cardiovascular disease often complicates optimal workup of lung nodules and treatment of lung cancer patients. Ideally, patients with radiographic lung lesions that are suspicious for primary or recurrent lung carcinoma either undergo biopsy to establish the diagnosis of malignancy prior to curative therapy or primary resection as a diagnostic and therapeutic procedure. However, pneumothorax rates with CT-guided biopsy for lung nodules are $4 \%-27 \%{ }^{[12,21-23]}$ with chest tube insertion reported in $1 \%-5 \%$ of cases ${ }^{[21,22]}$. Pulmonary hemorrhage has also been reported in $0.3 \%-4 \%$ of CT-guided biopsies ${ }^{[21-23]}$. The complication rate is not insignificant for CT-guided lung biopsy especially in patients with COPD with poor pulmonary function and emphysematous blebs. In the event that tissue cannot be obtained, radiography with CT and PET diagnose these suspicious lesions. Sensitivity of 18 -FDG PET for the diagnosis of lung cancer is $95 \%-100 \%{ }^{[24,25]}$ with very little associated morbidity.

Patients in this report were either medically unfit or unwilling to undergo biopsy, or biopsy was performed but was non-diagnostic. All patients had lesions that were radiographically consistent with malignancy to validate treatment. Multiple studies report on patients treated with SBRT with inclusion of patients without tissue diagnosis. In these studies, $22 \%-69 \%$ of patients did not have pathologic confirmation and were diagnosed based on malignant radiographic characteristics including FDG avidity, enlarging mass on CT, and spiculation ${ }^{[13-17]}$. Beitler et al. found no differences in overall survival ${ }^{[15]}$, and Ricardi et al. found no difference in cancer specific survival in patients treated with SBRT without pathology ${ }^{[14]}$. Inoue et al. reported on patients treated with small lung lesions that were radiographically diagnosed. They report local progression of $3.4 \%$ for lesions $\leq 20 \mathrm{~mm}$ and $5.3 \%$ for lesions $>20 \mathrm{~mm}^{[26]}$.

A report by Kelly et al. from M.D. Anderson Cancer Center describes the results of 36 patients treated with SBRT as salvage therapy for locally recurrent NSCLC after prior fractionated thoracic radiation therapy. Only 11 of these patients were treated with SBRT for in-field failures. With 15 months of follow up, local control is $92 \%$ for the entire group ${ }^{[27]}$. Coon et al. from University of Pittsburgh Cancer Institute reported on 26 patients treated with salvage lung SBRT, 12 of which were in-field failures of prior fractionated radiotherapy. With 12 months of follow up, local control is $92 \%$ for the locally recurrent population ${ }^{[28]}$.

The absolute local control in this study is $100 \%$ for primary patients and $71.4 \%$ for recurrent patients. The local control in our primary treatment population is comparable to prospective studies including the LCSG report on lobectomy and RTOG 0236 on SBRT. Control outcomes for primary patients are also similar to those reported for patients that did not undergo biopsy. The local control for the recurrent treatment population is comparable to those seen at other institutions though the literature is scarce on this topic. Since there were patients in this study with locally recurrent NSCLC, the main site of failure was distant.

In this report, none of the patients experienced grade 3 or greater acute or chronic toxicity. The follow up for many of the patients is short enough that chronic toxicity may not yet be experienced. Radiation pneumonitis, chest wall pain, brachial plexopathy, and damage to central structures would all be potential late complications. In the recently reported RTOG 0236, the rate of protocol specified Grade $3 / 4$ toxicity rate was $16.4 \%$ and overall Grade 3/4 toxicity rate was $27.3 \%$. Toxicity primarily manifested as pulmonary or upper respiratory in origin ${ }^{[11]}$. In our study we noted $40 \%$ of patients with radiographic pneumonitis, lung fibrosis, or opacities though these patients did not have clinical correlation.

Some radiation oncologists choose not to treat a patient that is medically unfit or unwilling to undergo tissue confirmation of a primary or recurrent lung carcinoma that is otherwise suitable for SBRT. The rationale for this perspective is that the patient's greatest risk of mortality is likely the comorbidities that prevent tissue biopsy as opposed to the cancer itself. However, Stephans et al. reported no difference in overall survival comparing patients with pathologic versus radiographic diagnosis, thus supporting the aggressive treatment of unbiopsied patients ${ }^{[29]}$. It can be difficult to predict causes of death in patients with early stage or low volume recurrence of malignancy due to competing comorbidities. It can be discouraging for a patient to discover that he may have cancer but cannot be treated due to his comorbidities or high risk of 
grave complications. A patient should have an informed discussion about his comorbidities, risks, and benefits of all treatment options ideally in a multidisciplinary setting.

\section{Conclusion}

Our study demonstrates that SBRT for the medically inoperable and unbiopsied patient is feasible with comparable control rate and toxicity profile to those patients with pathologic diagnosis. More study is needed to evaluate the role of functional imaging to replace invasive biopsy for the establishment of diagnosis in the medically inoperable patient with early stage lung cancer.

\section{Conflict of interest}

The authors declare that they have no competing interests.

\section{Authors' contributions}

Matthew Harkenrider, MD - original conceptualization of the study and design, collection of data, analysis of data, review of literature, writing manuscript; Matthew Bertke, MSE - collection of data, statistics, analysis of data, review of literature, figure and table generation, critical evaluation of manuscript; Neal Dunlap, MD - critical evaluation of manuscript, statistics, analysis of data, research supervision; Anthony Dragun, MD - original conceptualization of design of the study, critical evaluation of the manuscript, research supervision.

\section{References}

[1] Martini N, Bains MS, Burt ME et al. Incidence of local recurrence and second primary tumors in resected stage I lung cancer. J Thorac Cardiovasc Surg 1995;109(1):120-29. http://dx.doi.org/10.1016/S0022-5223(95)70427-2

[2] Ginsberg RJ, Rubinstein LV. Randomized trial of lobectomy versus limited resection for T1 No non-small cell lung cancer. Lung Cancer Study Group. Ann Thorac Surg 1995;60(3):615-622; discussion 622-613.

[3] Armstrong JG, Minsky BD. Radiation therapy for medically inoperable stage I and II non-small cell lung cancer. Cancer Treat Rev 1989;16(4):247-55. http://dx.doi.org/10.1016/0305-7372(89)90044-3

[4] Dosoretz DE, Katin MJ, Blitzer PH et al. Medically Inoperable Lung Carcinoma: The Role of Radiation Therapy. Semin Radiat Oncol 1996;6(2):98-104. http://dx.doi.org/10.1016/S1053-4296(96)80006-3

[5] Kaskowitz L, Graham MV, Emami B et al. Radiation therapy alone for stage I non-small cell lung cancer. Int J Radiat Oncol Biol Phys 1993;27(3):517-23. http://dx.doi.org/10.1016/0360-3016(93)90374-5

[6] Onishi H, Kuriyama K, Komiyama T et al. Clinical outcomes of stereotactic radiotherapy for stage I non-small cell lung cancer using a novel irradiation technique: Patient self-controlled breath-hold and beam switching using a combination of linear accelerator and CT scanner. Lung Cancer 2004;45(1):45-55. PMid:15196734 http://dx.doi.org/10.1016/j.lungcan.2004.01.004

[7] Nagata Y, Takayama K, Matsuo Y et al. Clinical outcomes of a phase I/II study of 48 Gy of stereotactic body radiotherapy in 4 fractions for primary lung cancer using a stereotactic body frame. Int J Radiat Oncol Biol Phys 2005;63(5):1427-31. PMid:16169670 http://dx.doi.org/10.1016/j.ijrobp.2005.05.034

[8] McGarry RC, Papiez L, Williams M et al. Stereotactic body radiation therapy of early-stage non-small-cell lung carcinoma: Phase I study. Int J Radiat Oncol Biol Phys 2005;63(4):1010-15. PMid:16115740 http://dx.doi.org/10.1016/j.ijrobp.2005.03.073

[9] Xia T, Li H, Sun Q et al. Promising clinical outcome of stereotactic body radiation therapy for patients with inoperable Stage I/II non-small-cell lung cancer. Int J Radiat Oncol Biol Phys 2006;66(1):117-25. PMid:16765528

http://dx.doi.org/10.1016/j.ijrobp.2006.04.013

[10] Fakiris AJ, McGarry RC, Yiannoutsos CT et al. Stereotactic body radiation therapy for early-stage non-small-cell lung carcinoma: Four-year results of a prospective phase II study. Int J Radiat Oncol Biol Phys 2009;75(3):677-82. PMid:19251380 http://dx.doi.org/10.1016/j.ijrobp.2008.11.042

[11] Timmerman R, Paulus R, Galvin J et al. Stereotactic body radiation therapy for inoperable early stage lung cancer. JAMA 2010;303(11):1070-76. PMid:20233825 http://dx.doi.org/10.1001/jama.2010.261 
[12] Priola AM, Priola SM, Cataldi A et al. Diagnostic accuracy and complication rate of CT-guided fine needle aspiration biopsy of lung lesions: A study based on the experience of the cytopathologist. Acta Radiol 2010;51(5):527-33. PMid:20429755 http://dx.doi.org/10.3109/02841851003691979

[13] Baumann P, Nyman J, Hoyer M et al. Outcome in a prospective phase II trial of medically inoperable stage I non-small-cell lung cancer patients treated with stereotactic body radiotherapy. J Clin Oncol 2009;27(20):3290-96. PMid:19414667 http://dx.doi.org/10.1200/JCO.2008.21.5681

[14] Ricardi U, Filippi AR, Guarneri A et al. Stereotactic body radiation therapy for early stage non-small cell lung cancer: Results of a prospective trial. Lung Cancer 2010;68(1):72-77. PMid:19556022 http://dx.doi.org/10.1016/j.lungcan.2009.05.007

[15] Beitler JJ, Badine EA, El-Sayah D et al. Stereotactic body radiation therapy for nonmetastatic lung cancer: An analysis of 75 patients treated over 5 years. Int J Radiat Oncol Biol Phys 2006;65(1):100-106. PMid:16517092 http://dx.doi.org/10.1016/j.ijrobp.2005.11.028

[16] Lagerwaard FJ, Haasbeek CJ, Smit EF et al. Outcomes of risk-adapted fractionated stereotactic radiotherapy for stage I non-small-cell lung cancer. Int J Radiat Oncol Biol Phys 2008;70(3):685-92. PMid:18164849 http://dx.doi.org/10.1016/j.ijrobp.2007.10.053

[17] Baumann P, Nyman J, Lax I et al. Factors important for efficacy of stereotactic body radiotherapy of medically inoperable stage I lung cancer. A retrospective analysis of patients treated in the Nordic countries. Acta Oncol 2006;45(7):787-95. PMid:16982541 http://dx.doi.org/10.1080/02841860600904862

[18] Timmerman R, McGarry R, Yiannoutsos C et al. Excessive toxicity when treating central tumors in a phase II study of stereotactic body radiation therapy for medically inoperable early-stage lung cancer. J Clin Oncol 2006;24(30):4833-39. PMid:17050868 http://dx.doi.org/10.1200/JCO.2006.07.5937

[19] Benedict SH, Yenice KM, Followill D et al. Stereotactic body radiation therapy: The report of AAPM Task Group 101. Med Phys 2010;37(8):4078-101. PMid:20879569 http://dx.doi.org/10.1118/1.3438081

[20] RTOG 0915 Protocol Information. www.rtog.org/ClinicalTrials/ProtocolTable/StudyDetails.aspx?study=0915. (26 March 2012, date last accessed).

[21] Laspas F, Roussakis A, Efthimiadou R et al. Percutaneous CT-guided fine-needle aspiration of pulmonary lesions: Results and complications in 409 patients. J Med Imaging Radiat Oncol 2008;52(5):458-62. PMid:19032391 http://dx.doi.org/10.1111/j.1440-1673.2008.01990.x

[22] Chakrabarti B, Earis JE, Pandey R et al. Risk assessment of pneumothorax and pulmonary hemorrhage complicating percutaneous co-axial cutting needle lung biopsy. Respir Med 2009;103(3):449-55. PMid:18977128 http://dx.doi.org/10.1016/j.rmed.2008.09.010

[23] Chojniak R, Isberner RK, Viana LM et al. Computed tomography guided needle biopsy: Experience from 1,300 procedures. Sao Paulo Med J 2006;124(1):10-14. PMid:16612456 http://dx.doi.org/10.1590/S1516-31802006000100003

[24] Dewan NA, Gupta NC, Redepenning LS et al. Diagnostic efficacy of PET-FDG imaging in solitary pulmonary nodules. Potential role in evaluation and management. Chest 1993;104(4):997-1002. PMid:8404239 http://dx.doi.org/10.1378/chest.104.4.997

[25] Sazon DA, Santiago SM, Soo Hoo GW et al. Fluorodeoxyglucose-positron emission tomography in the detection and staging of lung cancer. Am J Respir Crit Care Med 1996;153(1):417-21. PMid:8542152

[26] Inoue T, Shimizu S, Onimaru R et al. Clinical outcomes of stereotactic body radiotherapy for small lung lesions clinically diagnosed as primary lung cancer on radiologic examination. Int J Radiat Oncol Biol Phys 2009;75(3):683-87. PMid:19231107 http://dx.doi.org/10.1016/j.ijrobp.2008.11.026

[27] Kelly P, Balter PA, Rebueno N et al. Stereotactic body radiation therapy for patients with lung cancer previously treated with thoracic radiation. Int J Radiat Oncol Biol Phys 2010;78(5):1387-93. PMid:20381271 http://dx.doi.org/10.1016/j.ijrobp.2009.09.070

[28] Coon D, Gokhale AS, Burton SA et al. Fractionated stereotactic body radiation therapy in the treatment of primary, recurrent, and metastatic lung tumors: The role of positron emission tomography/computed tomography-based treatment planning. Clin Lung Cancer 2008;9(4):217-21. PMid:18650169 http://dx.doi.org/10.3816/CLC.2008.n.032

[29] Stephans KL, Djemil T, Reddy CA et al. A comparison of two stereotactic body radiation fractionation schedules for medically inoperable stage I non-small cell lung cancer: The Cleveland Clinic experience. J Thorac Oncol 2009;4(8):976-82. PMid:19633473 http://dx.doi.org/10.1097/JTO.0b013e3181adf509 